\title{
Evaluating the impact of audit interventions on accidental removal of critical care devices in the intensive care unit - Clinical Audit Project
}

\author{
Alfateh Sayed M. Noor ${ }^{1 *}$, Abdulrahman Alharthy ${ }^{1}$, Mohammed H. Lhmdi ${ }^{1}$, Hind Elshareef ${ }^{2}$, Zohdi Farea ${ }^{1}$, Mohammad Bokhamseen ${ }^{1}$, \\ Huda Mhawish ${ }^{1}$, Waleed Th. Aletreby ${ }^{1}$, Abdullah Balhamar ${ }^{1}$, Ahmed F. Mady $^{1}$ \\ ${ }^{1}$ Critical Care Department, King Saud Medical City, Riyadh, KSA \\ ${ }^{2}$ critical care department, King Saud University Medical City, Riyadh, KSA
}

Corresponding Author: Alfateh Sayed M. Noor, Critical Care Department, King Saud Medical City, Riyadh, KSA.

Received date: September 21, 2020; Accepted date: October 02, 2020; Published date: October 05, 2020

Citation: Alfateh S. M. Noor, Alharthy A., Mohammed H. Lhmdi, Elshareef H., Farea Z., Bokhamseen Md., Mhawish H., Waleed Th. Aletreby, Balhamar A., Ahmed F. Mady, (2020) Evaluating the impact of audit interventions on accidental removal of critical care devices in the intensive care unit - Clinical Audit Project J, Clinical Medical Reviews and Reports. 2(7); DOI:10.31579/2690-8794/047

Copyright: (C) 2020, Alfateh Sayed M. Noor, This is an open access article distributed under the Creative Commons Attribution License, which permits unrestricted use, distribution, and reproduction in any medium, provided the original work is properly cited.

\begin{abstract}
Accidental critical care device removals in intensive care units (ICUs) are serious preventable incidents that have major implications. The study aimed to understand possible causes of such events and identify interventions that reduced their occurrence. The researchers conducted a single-center audit by collecting patient data and bundle forms for accidental device removal across two consecutive periods; they retrospectively reviewed the data from the first period (August 1, 2019 to January 31,2020 ) and prospectively analyzed the data from the bundle forms obtained in the second (February 1, 2020 to July 31,2020 ). From the findings of the first period, the researchers designed an intervention comprising nurses' adherence to a care bundle checklist and an educational campaign for the care-taking team and applied it in the second period. Patients either accidentally removed the central venous lines secondary to agitation $(47 \%)$, or it happened by loss of catheter securement $(21 \%)$, or during daily care $(17 \%)$ or patient transfer $(13 \%)$. Such inadvertent incidents resulted in reinsertion with another central venous line (69\%), agitation due to sedation interruption (47\%), development of hemodynamic instability because of interruption of inotrope administration (30\%), significant bleeding that required intervention (21\%), and no complications (39\%). The overall nurses' compliance to the care bundle checklist improved from $87 \%$ to $97 \%$ after introduction of the intervention and the number of devices found in place increased. Therefore, the designed care bundle checklist and educational program successfully decreased the accidental removal of critical care devices.
\end{abstract}

Key words: ICU; critical care devices; accidental removal; patient management

\section{Introduction}

Working in the intensive care unit (ICU) is stressful because of the critical medical conditions managed therein that warrant important decisions and could have serious implications. Furthermore, taking care of critically ill patients with different needs adds to this stress because the treatment of such patients extends beyond standard care to assigning additional importance toward avoiding complications and possible adverse events. One such important event is the accidental removal of devices including life sustaining devices such as Endo_tracheal tubes or supportive devices such as NGT and central venous catheters. It is a relentless concern of critical care staff to avoid such preventable events that can alter the course of a patients' stay in the department. In order to start a project aimed at decreasing these incidents, we found it paramount to first understand the possible causes of such events and then identify the practical interventions needed to reduce their likelihood of occurrence. We collected six months' data of the common devices accidentally removed and the relevant clinical information of the patients concerned. After dissecting the etiology and confounding factors, we designed an educational program including lectures and orientations targeting the ICU staff to improve their knowledge of the subject and a care bundle checklist for the nurses to comply with for each patient. Our aim was to assess the nurses' compliance to the bundle form and to assess if this compliance impacted the incidence of accidental device removal.

\section{Materials and methods}

\section{A) Study population and sampling:}

This audit was conducted in the Adult Critical Care Department of King Saud Medical City, Riyadh, Saudi Arabia, all adult patients (age >18 years) admitted to the hospital and had a device inserted were included in our study, there was no sampling process as our target was to recruit as much patients as we can. No inclusion or exclusion criteria had been applied.

\section{B) Study objective and variables:}

The aim of this audit was to check the nurse compliance to accidental removal of device bundle checklist, and to determine if the adherence to this bundle and our training sessions will impact the incidence of device removal.

The prevention of accidental removal of devices checklist (care bundle checklist) that we followed was composed of two parts. The first part was regarding the risk factors of device removal and included the following criteria: 
- The number of critical care devices attached to the patient were $>4$.

- $\quad$ The patient's Richmond Agitation Sedation Scale score was 1+ or more.

- The patient exhibited confusion/delirium.

- There was interruption of sedation/occurrence of spontaneous awakening trial.

- The patient was scheduled for extubation/was on spontaneous breathing trial.

- The patient was physically restrained.

The second part was regarding precautionary measures that prevent accidental device removal if a patient has two or more of the abovementioned risk factors; it was composed of the following elements:

- "Identify the devices attached to the patient"

- "Trace the devices from the beginning to the end"

- "Ensure that the devices are not entangled"

- "Ensure that all devices can freely move with the patient"

- "Ensure that no devices are bearing any weight"

- "Ensure that no devices are attached or fixed to the bedside"

- "Ensure that the devices are properly fixed to the patient"

- "Ensure that the nurse to patient ratio is 1:1"

To determine the incident of device removal and its risk factors and complication another form was used. This form had 3 components as following:

- Distribution of device removal by the type of the device.
- Complications of the devices removal.

\section{C) Study period and data collection:}

The study involved two six-month consecutive periods; the first was from August 1, 2019 to January 31, 2020, and the second was from February 1, 2020 to July 2020. Data from the first period included the files of patients who experienced accidental device removal; these were reviewed retrospectively. In the second period, we conducted a prospective analysis of the bundle forms (care bundle checklist) during and after our educational campaign, which consisted of lectures, presentations, and daily clinical rounds.

\section{D) Work and intervention:}

The target of our campaign was to increase the nurses' compliance to the care bundle checklist to $100 \%$ and to decrease the incidence of preventable critical care device removal to zero. Our strategy consisted of a series of lectures for all ICU staff by the Quality Department team, a daily assessment conducted by the nurses-in-charge to ensure the compliance of bedside nurses to the care bundle checklist, the submission of a weekly report to the campaign committee regarding the nurses' compliance to the care bundle form, the establishment of a call center run by personnel from the Quality Department who answered any query concerning the care bundle, and a monthly analysis of the data to detect any discrepancies to make corrections accordingly.

\section{E) Statistical analysis:}

The collected data entered in excel sheet. A simple statistical analysis was performed by excel program. The frequency of accidental device removal during the audit period and the major outcomes of such events were determined. Frequency and percentage of each risk factors also described. Finally, the number and percentage of the nurse's compliance with the care bundle checklist before, during, and after the campaign were calculated.

\section{Results}

- $\quad$ Risk factors for the devices removal

\section{causes}



\section{Figure 1: Causes of accidental central line removal $(\mathrm{N}=23)$}

As seen in Figure 1, the vast majority of accidental central line removals were done by the patients themselves secondary to agitation (47\%). Accidental critical care device removals because of loss of catheter securement, or during daily care or patient transfer were $21 \%$, $17 \%$, and $13 \%$, respectively. 


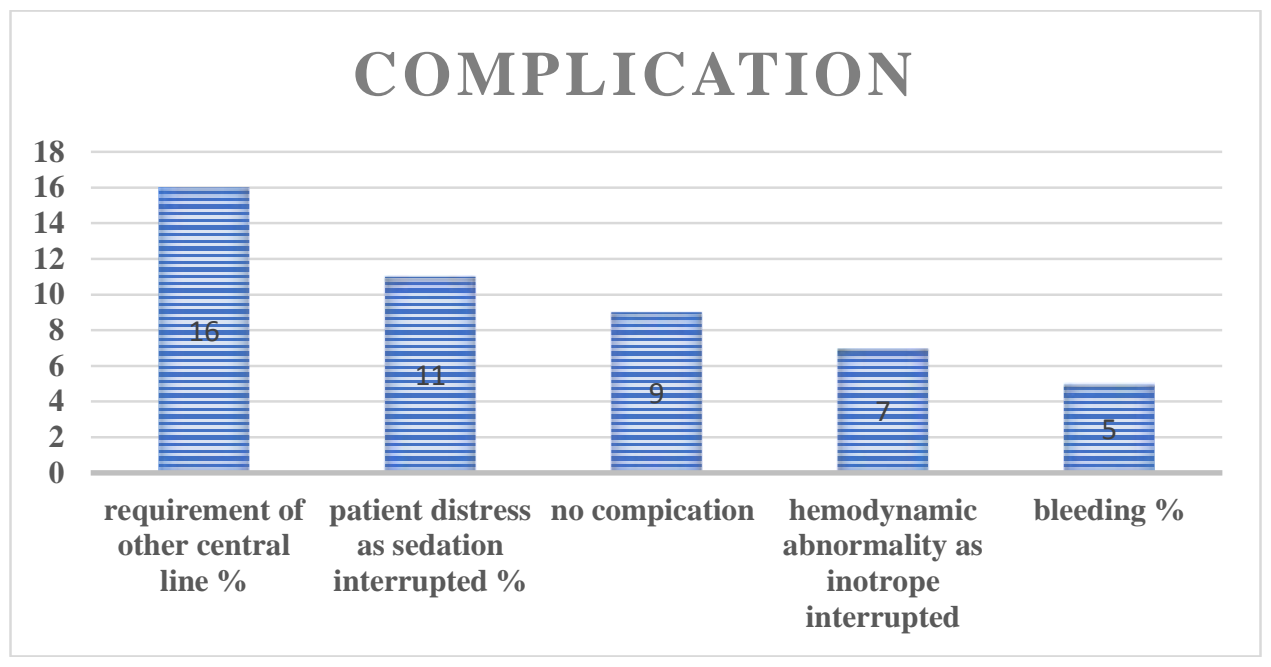

Figure 2: Outcomes of accidental central line removal

Most patients ( $n=16 / 23,69 \%)$ with accidental central venous line removal required another device insertion (Figure 2). Other most common complications of accidental removal of central venous line were agitation due to sedation interruption (47\%), development of hemodynamic instability because of interruption of inotrope administration (30\%), and significant bleeding that required intervention (21\%). No complications were seen in $39 \%$ of the patients.

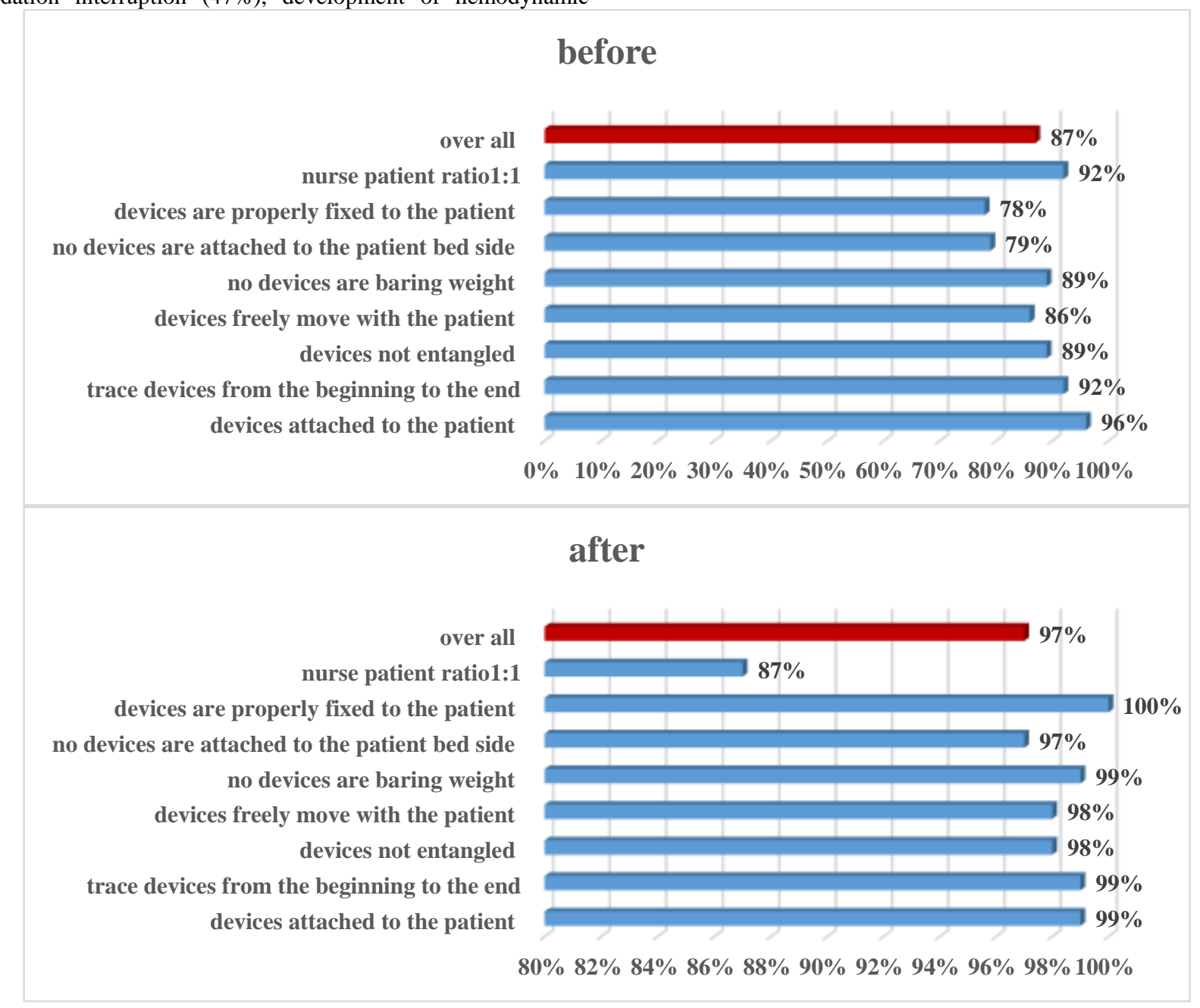

Figure 3: The nurses' compliance to the bundle before (A) and after (B) introduction of the intervention. 
The overall compliance to the care bundle checklist improved from $87 \%$ to $97 \%$ after introduction of our intervention (Figure 3). Additionally, the compliance to each individual element of the checklist improved except for the requirement of 1:1 nurse to patient ratio that could be attributed to a staff crisis during the surge of coronavirus disease cases. Figure 4 shows the trends of accidental removal of three critical care devices evaluated during the study.
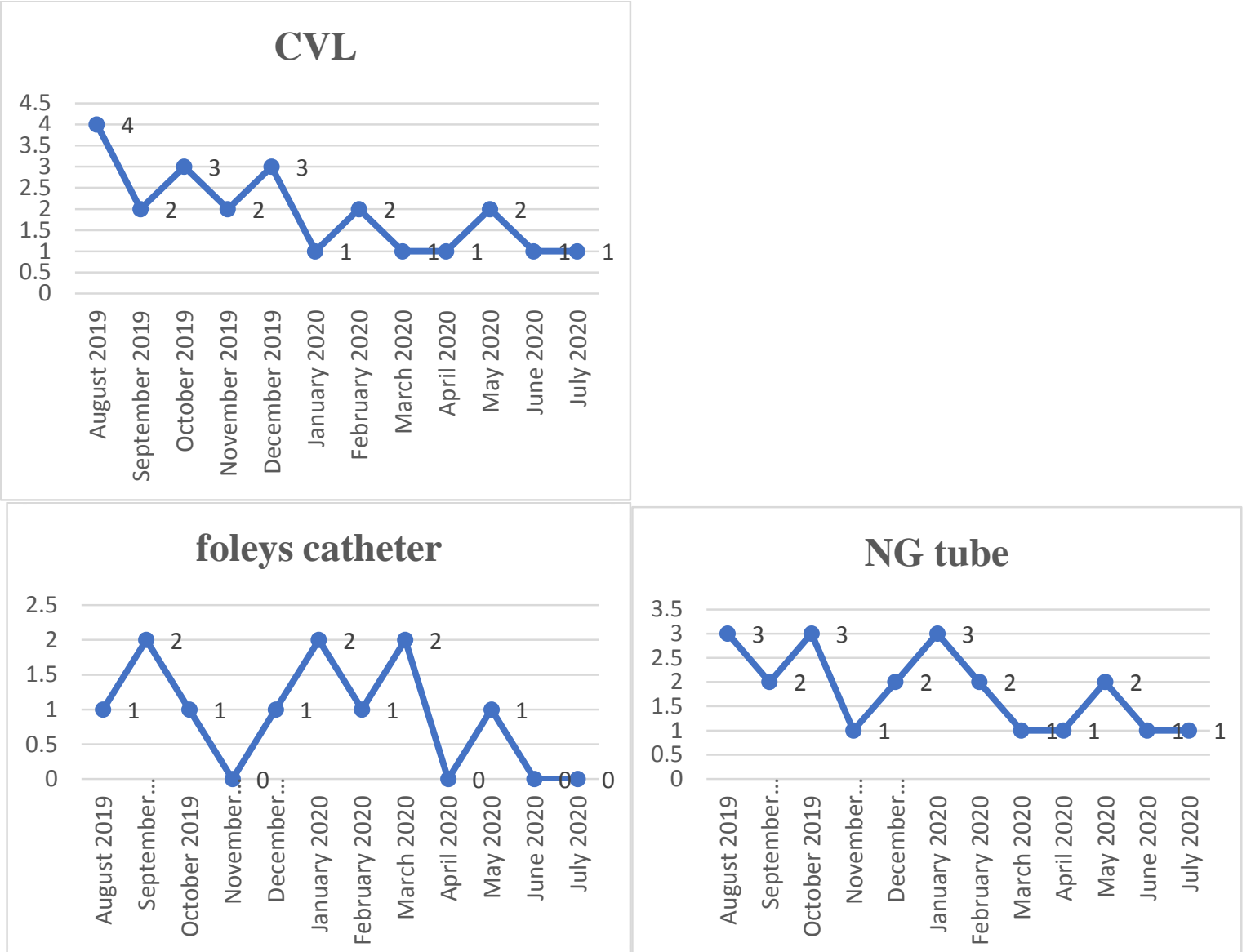

Figure 4: The rates of accidental device removal of (A) central venous line (CVL), (B) Foley catheter, and (C) nasogastric tube (NG tube) during the study period (before and after the intervention)

As seen in Table 1, there was a marked improvement in the number of critical care devices in place, during and after the intervention.

\begin{tabular}{|l|c|c|c|c|}
\hline & \multicolumn{2}{|c|}{ Before intervention } & \multicolumn{2}{c|}{ During and after intervention } \\
\hline Central venous line & 167 & $15(8.9 \%)$ & 199 & $8(2.4 \%)$ \\
\hline Foley catheter & 189 & $7(3.7 \%)$ & 219 & $4(1.8 \%)$ \\
\hline Nasogastric tube & 178 & $14(7.8 \%)$ & 209 & $8(3.8)$ \\
\hline
\end{tabular}

Table 1: Rate of accidental removal of devices expressed according to the number of tubes or catheters in place

\section{Discussion}

Different devices and catheters attached to patients are necessary in critical care departments. However, they may incur various complications and side effects related to their insertion or accidental removal. Such adverse events are important to discuss, as they are largely preventable. In our study, we show that accidental removal of critical care devices can be prevented by proper training and education of the care-taking staff. Our study also highlights the importance of complying with a care bundle checklist that addresses common causes of accidental removal of critical care devices such as lack of proper sedation.

In particular, the dislodgement rates of central venous catheters have been estimated at $1.8 \%-24.5 \%$, with greater than five million catheters dislodged per year [1-5]. In our hospital, this incidence was $8.9 \%$ (table
1) and was of notable importance considering the potential increase in risk of morbidity and mortality it entails [6] in addition to other implications such as prolonged hospitalization, insertion of other venous catheters and related complications, and further financial burden [7]. Moreover, our observations revealed specific complications such as hemodynamic instability in 30\% of the patients (Figure 2). Several factors were associated with and could possibly cause the accidental dislodgement of the venous catheters; the most common contributors were patient agitation (47\%) and loss of central line securement (21\%; Figure 1).

With the possible causes and contributors in mind, we started daily lectures and weekly presentations, targeting the ICU staff on the importance of avoiding these kinds of events and equipping them with knowledge regarding the management of patients who have different critical care devices attached to them. Furthermore, we added the care 
bundle checklist in every patients' file and ensured that it was discussed and presented in the daily clinical rounds.

Our main target audience for the educational activity were the nurses, as we believe that they have a major role in patient management and have the longest contact time with the ICU patients. Therefore, it was important for the care bundle to be implemented and designed based on the nurses' needs, and experiences. However, we also wanted this effort to involve the entire team taking care of the patient so we emphasized the importance of a multidisciplinary approach involving respiratory therapists and physicians; extensive evidence suggests that this is the most effective way to obtain better results $[8,9]$.

After implementing these measures, we analyzed the findings and found a remarkably positive result (Figure 3 and 4). There was a notable improvement in the rate of nurses' compliance to the care bundle checklist that translated into a clear reduction in the accidental removal of critical care devices, such as central venous catheters, Foley catheters, and nasogastric tubes (Figure 3).

\section{Conclusion}

Dislodgement of life-saving devices have serious consequences in critical care departments and efforts should be made to decrease the incidence of these preventable events. Addressing the possible causes and designing a care bundle checklist, which ensures compliance to prevention measures, in addition to a targeted training of the care-taking staff could lead to satisfactory results that translate into better patient management.

\section{Declaration of conflicting interest:}

No conflict of interest.

\section{Funding:}

No funds provided to this work

\section{References}

1. Dugger B, Macklin D, Rand B. (1994) Veni-Gard versus standard dressings on hemodynamic catheter sites. Dimens Crit Care Nurs. 13(2):84-89.

2. Wood D, Bowe-Geddes LA. (1997) A comparative retrospective analysis of two securement techniques for peripherally inserted central catheters (PICC) and midlines in the homecare setting. J Vasc Access. 2(3):11-16.

3. Yamamoto AJ, Solomon JA, Soulen MC, et al. (2002) Sutureless securement device reduces complications of peripherally inserted central venous catheters. J Vasc Interv Radiol. 13(1):7781.

4. Moureau N, Iannucci A. (2003) Catheter securement: trends in performance and complications associated with the use of either traditional methods or an adhesive anchor device. J Vasc Access. 8(1):29-33.

5. Schears GJ, Frey AM. (2001) StatLock catheter securement device reduces central venous catheter complications. Patient Saf. 1:28-37.

6. Frey AM, Schears G. (2001) Dislodgment rates and impact of securement methods for peripherally inserted central catheters (PICCs) in children. Pediatr Nurs. 27(2):185-193.

7. Dychter SS, Gold DA, Carson D, Haller M. (2012) Intravenous therapy: a review of complications and economic considerations of peripheral access. J Infus Nurs. 35(2):84-91.

8. Reader TW, Flin R, Mearns K, Cuthbertson BH. (2009) Developing a team performance framework for the intensive care unit. Crit Care Med. 37(5):1787-1793.

9. Manser T. (2009) Teamwork and patient safety in dynamic domains of healthcare: a review of the literature. Acta Anaesthesiol Scand.53 (2):143-151.



This work is licensed under Creative Commons Attribution 4.0 License

To Submit Your Article Click Here: Submit Article
Ready to submit your research? Choose Auctores and benefit from:

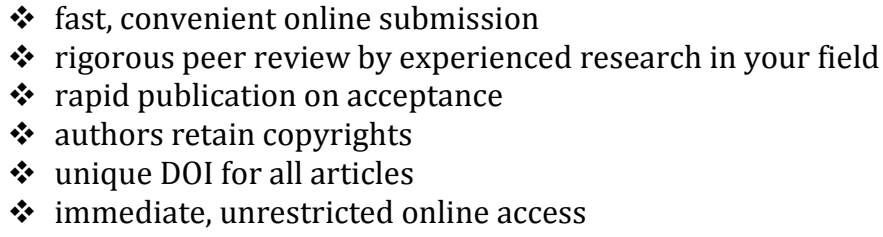

At Auctores, research is always in progress.

Learn more www.auctoresonline.org/journals/clinical-medicalreviews-and-reports 